\title{
Exclusive breastfeeding and mothers' employment status in Gondar town, Northwest Ethiopia: a comparative cross- sectional study
}

Dawit Alemayehu Chekol', Gashaw Andargie Biks², Yalemzewod Assefa Gelaw ${ }^{3}$ and Yayehirad Alemu Melsew ${ }^{3 *}$

\begin{abstract}
Background: Exclusive breastfeeding is defined as feeding an infant breast milk only, for the first six months. In Ethiopia, more than half of infants do not receive exclusive breastfeeding. Workplace barriers contribute to these low rates of exclusive breastfeeding practices. Understanding the sociodemographic, health related, behavioral and economic factors is crucial to promote the practice of exclusive breastfeeding in Ethiopia. Therefore, the aim of this study was to assess the extent of exclusive breastfeeding practice and associated factors among employed and unemployed mothers with children of age 7-12 months in Gondar town, northwest Ethiopia, 2015.
\end{abstract}

Methods: A community based comparative cross-sectional study was conducted in October 2015. Simple random sampling technique was used to select 649 eligible mothers with children age 7-12 months during the study period. A structured and pretested interviewer administered questionnaire was used to collect the data. Three logistic regression models: whole sample, employed and not employed, were fitted.

Results: A total of 649 (333 unemployed and 316 employed) mothers were interviewed. The mean duration of mothers to exclusively breastfeed was 4.77 months ( \pm 1.36 Standard Deviation [SD]). Exclusive breastfeeding was higher among unemployed $48.0 \%$ with $95 \%$ Confidence Interval (CI) (42.0\%, 54.0\%) than employed (20.9\%) with $95 \% \mathrm{Cl}(16.0 \%, 25.0 \%)$. Parity of three children and above (Adjusted Odds Ratio [AOR] $=3.48$ ), and having social support $(A O R=3.45$ ) were positively associated with exclusive breastfeeding while poor knowledge $(A O R=0.30)$, wealth index of the medium level $(A O R=0.38)$ were negatively associated among employed mothers. In the case of unemployed mothers, vaginal delivery $(A O R=2.60)$ and having social support ( $A O R=3.03$ ) were positively associated with exclusive breastfeeding while, poor knowledge ( $A O R=0.28)$, and not having antenatal care (AOR $=0.56)$ were negatively associated.

Conclusions: The overall exclusive breastfeeding practice of mothers was low. However, unemployed mothers breastfeed more than employed mothers. Providing a special support for employed mothers and revising either the legislation of the two month postpartum maternity leave or applying different alternatives is recommended.

Keywords: Exclusive breastfeeding, employment status, Ethiopia

\footnotetext{
* Correspondence: 078yayu@gmail.com

${ }^{3}$ Department of Epidemiology and Biostatistics, Institute of Public Health,

College of Medicine and Health Science, University of Gondar, Gondar,

Ethiopia

Full list of author information is available at the end of the article
} 


\section{Background}

The experience of mothers in many countries including Ethiopia doesn't seem to follow the expected international recommendation for exclusive breastfeeding [1]. Many infants are neither breastfed during their first hours of life with colostrum or are exclusively breastfed during their first six months. These practices may expose them to infectious diseases and have a negative impact on their growth and development [2].

Globally, the rate of exclusive breastfeeding (EBF) is $43 \%$ in 2015, while in Sub-Saharan Africa and East Africa it was $31 \%$ and $42 \%$, respectively [3]. The prevalence of exclusive breastfeeding in Ethiopia among children of age 4-6 month was less than 50\% [4-6]. In Ethiopia, the maternity leave offered during the postpartum period is only two months. This could affect working mothers not to exclusively breastfeed for the first six months [4]. Studies indicate that significant difference $(10-30 \%)$ was observed between employed and unemployed mothers on the practice of exclusive breastfeeding [4, 5]. In Southeast Ethiopia, a study found that only $33 \%$ of employed mothers practiced EBF while $73 \%$ of unemployed mothers feed their children exclusively for the first six months [7]. This difference was a little lower in a study conducted in the north western part of the country which reported $44 \%$ and $65 \%$ of EBF among employed and unemployed mothers, respectively [8].

Maternal employment affects child caring time and is reported to be the major reason for low rates of EBF and also the lower duration of breastfeeding $[9,10]$.

The government of Ethiopia has recognized the problem of low exclusive breastfeeding practice in the country and has declared the annual "exclusive breastfeeding day" at national level, which is on 1st February [11]. Contrariwise, as the government is promoting women's employment, with affirmative actions too, the practice of exclusive breastfeeding became lower. By investigating the level of exclusive breastfeeding practice and its associated factors in comparison with women's employment status, this study aimed at providing the evidence for policy makers to plan and implement an approach for solving the problem.

\section{Methods}

\section{Study design and setting}

A community based comparative cross-sectional study was conducted from October 1-30, 2015. The two comparison study groups were employed and unemployed mothers. The study was conducted in Gondar Town, Northwest Ethiopia. Gondar town is located at $737 \mathrm{~km}$ from the capital of Ethiopia, Addis Ababa. The town administration is organized into 12 urban kebeles (smallest administrative units). Based on the 2007 national population census projections, the town has a total of urban population of 206,987 and among these 8002 were infants, aged less than one year, from which are 6263 were children aged between 7 and 12 months [11].

\section{Study population and sampling}

All mothers having children of age 7-12 months and living in the town administration during the study period were included in the study. However, employed and unemployed mothers with children of age 7-12 months who were critically ill and unable to be interviewed were excluded.

The sample size was determined using Epi info statistical software version 7 by using 'two population' proportion formula. In a similar study conducted by Mequanint [12] prevalence of exclusive breastfeeding differences among employed and unemployed mothers were found to be $44 \%$ and $65 \%$, respectively. A confidence level of $95 \%$, a power of $90 \%$, a design effect of $2 \%$ and a $5 \%$ nonresponse rate, the final sample size $n=618+31=649$. Finally, 316 employed and 333 unemployed eligible mothers were taken.

A multistage sampling technique was used to reach study participants. The town has 12 urban kebeles from these five kebeles were selected randomly. In the five selected kebeles, the total number of illegible mothers was estimated, household code numbers were given separately for employed and unemployed mothers. Following coding each household, the total sample size of the study was proportionally assigned to the five selected kebeles. Using the code numbers as a sampling frame study participants were selected randomly with computer generated random numbers (Fig. 1). Households were visited during working days to interview unemployed mothers whereas employed mothers were interviewed during the weekends.

\section{Data collection and analysis}

The pretested structured interviewer administered questionnaire was used to collect data. The questionnaire consisted of six parts: sociodemographic characteristics, economic indicators, birth related factors, exclusive breastfeeding related factors, knowledge, attitude and practice about exclusive breastfeeding and health service related factors.

The questionnaire was first developed in English and translated to Amharic, the local language. Ten trained data collectors collected the data under the continuous supervision of principal investigators.

Data were entered using EPI-INFO version 3.5.3 and then exported to SPSS version 20 for analysis. Descriptive and summary statistic was carried out to describe study participants according to different characteristics, and proportions were computed to find out the prevalence of exclusive breastfeeding (EBF). Binary logistic 


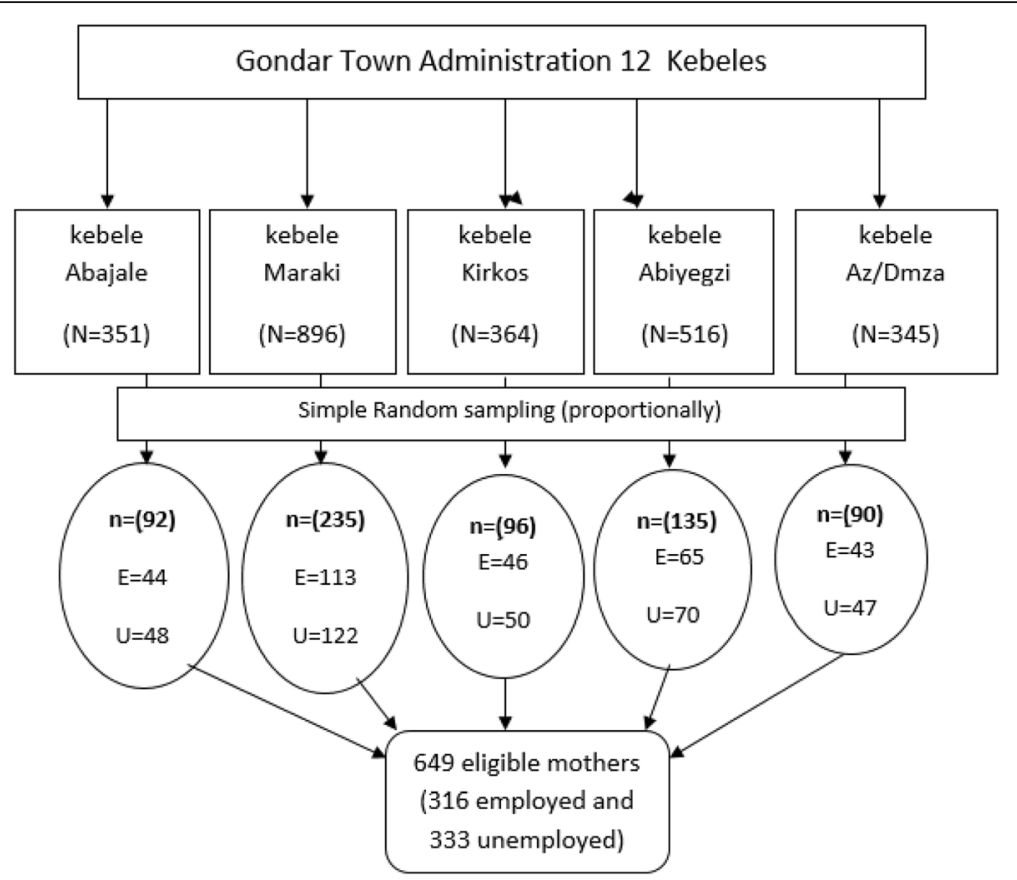

Fig. 1 Schematic presentation of sampling procedure of the study

regression was fitted to identify factors associated with exclusive breastfeeding practice. Three models were fitted; first for the whole sample (employed and unemployed mothers combined), second for employed mothers only and the third for unemployed mothers. Adjusted odds ratios (AOR) with 95\% confidence interval $(\mathrm{CI})$ were used to measure the strength and significance of the association. The $p$ values of less than 0.05 were considered as a statistically significant association.

\section{Terms and operational definitions}

Employed mothers: mothers who work outside the home for income in addition to the work they perform at home in raising their children [13].

Knowledge of mother: mothers' information on the advantages and recommended duration of exclusive breastfeeding. Mothers were asked six knowledge related questions and each correct answer was given a value of 1 and an incorrect answer a value of 0 . After computing the sum for each respondent and mean, it was dichotomized into good knowledge $\geq$ mean, poor knowledge $<$ mean.

Attitude: there were three attitude related questions and mothers who respond the right response to all the three questions the will be categorized as having a good attitude.

Practiced EBF: mothers who fed breast milk only for the first six months.

Predominant breastfeeding: the practice of feeding breast milk along with water [1].
Mixed breastfeeding: the practice of feeding breast milk along with food [1].

Early initiation of breastfeeding: infants who were put to the breast within one hour of birth [1].

Prelacteal feeding: children who have been given something other than breast milk during the first three days of life [1].

\section{Results}

\section{Sociodemographic characteristics}

A total 649 mothers having children of age 7-12 months were interviewed. The mean age mothers were 28.4 years ( \pm 4.8 years) and the mean age of children was 8.9 months ( \pm 3.604 months). Of the employed mothers $96(30.4 \%)$ were government employed. The majority, $89.5 \%$, of the participants attended secondary education and above (Table 1).

\section{Knowledge and attitude of mothers towards exclusive breastfeeding}

The majority, $80.0 \%$, and $83.1 \%$, of participants, reported they had good knowledge and attitude about exclusive breastfeeding, respectively. The proportion of knowledge on has no significance difference in employment status (Table 1).

\section{Health related characteristics}

The majority, $89.6 \%$, of participants (employed $=282$ : unemployed $=300$ ) gave birth at health center by a skilled attendant. The majority of participants, $94.5 \%$ 
Table 1 Sociodemographic, knowledge and attitude characteristics of employed and unemployed mothers in Gondar town, northwest Ethiopia, October 2015

\begin{tabular}{lll}
\hline Variables & Maternal employment & \\
\cline { 2 - 3 } & Employed $n=316$ & Unemployed $n=333$ \\
& Number (\%) & Number (\%)
\end{tabular}

\begin{tabular}{lll}
\hline Sex of child & & \\
Male & $150(47.5)$ & $173(52.0)$ \\
Female & $166(52.5)$ & $160(48.0)$
\end{tabular}

Maternal age

\begin{tabular}{|c|c|c|}
\hline $18-23$ & $25(7.9)$ & $59(17.7)$ \\
\hline $24-29$ & $153(48.9)$ & $155(46.5)$ \\
\hline$>=30$ & $138(43.7)$ & 119 (35.7) \\
\hline \multicolumn{3}{|l|}{ Parity } \\
\hline 1-2 children & $176(55.7)$ & 215 (64.6) \\
\hline 3 and above children & $140(44.3)$ & $118(35.4)$ \\
\hline \multicolumn{3}{|l|}{ Marital status } \\
\hline Married & $267(84.5)$ & $314(94.2)$ \\
\hline Single & $17(5.4)$ & $1(0.3)$ \\
\hline Divorced & $26(8.2)$ & $14(4.2)$ \\
\hline Widowed & $6(1.9)$ & $4(1.2)$ \\
\hline \multicolumn{3}{|l|}{ Ethnicity } \\
\hline Amhara & $243(76.9)$ & 279 (83.8) \\
\hline Qimant & $26(8.2)$ & $17(5.1)$ \\
\hline Tigrie & $38(12.0)$ & $36(10.8)$ \\
\hline Others & $9(2.8)$ & $1(0.3)$ \\
\hline \multicolumn{3}{|l|}{ Maternal education } \\
\hline No formal education & $35(11.1)$ & 45 (13.5) \\
\hline Only read and write & $33(10.4)$ & $59(17.7)$ \\
\hline Primary & $36(11.4)$ & $81(24.3)$ \\
\hline Secondary & $114(36.1)$ & 122 (36.6) \\
\hline Higher & $98(31.0)$ & $26(7.8)$ \\
\hline \multicolumn{3}{|l|}{ Husband education } \\
\hline No formal education & $21(11.1)$ & $36(10.8)$ \\
\hline Can read and write & $35(10.4)$ & $60(18.0)$ \\
\hline Primary & $34(11.4)$ & $58(17.4)$ \\
\hline Secondary & $104(36.1)$ & 118 (35.4) \\
\hline Higher & $122(31.0)$ & $61(18.3)$ \\
\hline \multicolumn{3}{|l|}{ Religion } \\
\hline Orthodox Christian & $228(72.2)$ & $212(63.7)$ \\
\hline Muslim & $74(23.4)$ & 109 (32.7) \\
\hline Protestant & $10(3.2)$ & $6(1.8)$ \\
\hline Catholic & $3(0.9)$ & $2(0.6)$ \\
\hline
\end{tabular}

Table 1 Sociodemographic, knowledge and attitude characteristics of employed and unemployed mothers in Gondar town, northwest Ethiopia, October 2015 (Continued)

\begin{tabular}{lll}
\hline Other & $1(0.3)$ & $4(1.2)$ \\
Attitude towards EBF & & $287(86.2)$ \\
Good attitude & $252(79.7)$ & \\
$\begin{array}{l}\text { Knowledge on EBF } \\
\text { Good knowledge }\end{array}$ & $253(80.1)$ & $271(81.4)$ \\
\hline
\end{tabular}

and $92.2 \%$, practiced breastfeeding their children immediately within one hour of birth, respectively. Furthermore, $92.6 \%$ and $98.5 \%$, employed and unemployed mothers were informed about exclusive breastfeeding during any of their antenatal care visits and had support from their partner, respectively (Table 2).

The main reasons reported by employed mothers for not practicing exclusive breastfeeding were that working was a hindrance $84(26.6 \%)$, and concern about the amount of milk 23 (7.3\%) immediately after birth.

\section{Exclusive breastfeeding}

The overall exclusive breastfeeding practice was 34.8\% (95\% CI 33.0\%, 36.7\%). The mean (SD) duration that infants received breast milk only was $4.8( \pm 1.4)$ month. A total of $20.9 \%$ (95\% CI 16.0\%, 25.0\%) employed mothers

Table 2 Health service related factors of employed and unemployed mothers in Gondar town, northwest Ethiopia, October, 2015

\begin{tabular}{|c|c|c|}
\hline \multirow[t]{2}{*}{ Variables } & \multicolumn{2}{|l|}{ Maternal employment } \\
\hline & Employed $(n=316)$ & Unemployed $(n=333)$ \\
\hline \multicolumn{3}{|l|}{ Place of birth } \\
\hline Home & $34(10.8)$ & $33(9.9)$ \\
\hline Health facility & $282(89.2)$ & $300(90.1)$ \\
\hline \multicolumn{3}{|l|}{ Mode of delivery } \\
\hline Vaginal delivery & $258(81.7)$ & $279(83.7)$ \\
\hline Caesarean section & $58(18.3)$ & $54(16.3)$ \\
\hline \multicolumn{3}{|c|}{$\begin{array}{l}\text { Timely initiation of BF / } \\
\text { within } 1 \mathrm{~h}\end{array}$} \\
\hline Yes & $205(64.9)$ & $236(70.1)$ \\
\hline \multicolumn{3}{|c|}{$\begin{array}{l}\text { Any non-breastmilk given } \\
\text { during the first } 3 \text { days }\end{array}$} \\
\hline Yes & $73(23.1)$ & $81(24.3)$ \\
\hline \multicolumn{3}{|l|}{ Frequency of EBF/24 h } \\
\hline$<9$ times & $132(41.8)$ & $184(58.2)$ \\
\hline 9 and above times & $94(28.2)$ & $239(71.8)$ \\
\hline \multicolumn{3}{|l|}{ Having social support } \\
\hline Yes & $234(74.1)$ & $289(86.9)$ \\
\hline \multicolumn{3}{|l|}{ Antenatal care } \\
\hline Yes & $232(73.4)$ & $248(74.5)$ \\
\hline
\end{tabular}


and 48.0\% (95\% CI 42.0\%, 54.0\%) unemployed mothers practiced exclusive breastfeeding.

\section{Factors associated with exclusive breastfeeding practice} The descriptive statistics comparing sociodemographic, knowledge and attitude characteristics showed a significant difference along the employment status of mothers. Exclusive breastfeeding, marital status, attitude, social support and household socioeconomic positions were significantly different along with the employment status of mothers (Additional file 1).

We fitted three different models to assess exclusive breastfeeding practice. The first model was fitted to assess the overall factors of exclusive breastfeeding practice. Variables such as knowledge, attitude, and employment status were significantly associated with exclusive breastfeeding practice regardless of employment status.

Mothers who had poor attitude (AOR 0.13, 95\% CI 0.05, 0.31 ), and poor knowledge (AOR $0.44,95 \%$ CI 0.24, 0.78) were less likely to practice exclusive breastfeeding than their counterparts. Mothers who were unemployed were 3.4 times more likely to practice exclusive breastfeeding than employed mothers (AOR 3.43, 95\% CI 2.38, 4.95) (Table 3).

The second model was fitted only for unemployed mothers. Accordingly, knowledge on exclusive breastfeeding, social support, history of antenatal (ANC) care follow up and mode of delivery showed a significant association (Table 4). Unemployed mothers who had poor knowledge on exclusive breastfeeding were $72.2 \%$ less likely to practice exclusive breastfeeding compared to those who had good knowledge (AOR 0.28, 95\% CI 0.14, 0.54 ) and mothers who had no social support were $66.6 \%$ less likely to breastfeed exclusively as compared with those who were supported (AOR 0.33, 95\% CI 0.16, 0.71 ). In addition, mothers who had antenatal care follow up as per the recommended frequency were 1.8 times more likely to breastfeed exclusively as compared with to those who had no antenatal care follow up (AOR $0.56,95 \%$ CI $0.32,0.98$ ) and mothers who birthed by spontaneous vaginal mode were 2.5 times more likely to breastfeed exclusively when compared with those who were delivered by caesarean section (AOR 2.60, 95\% CI $1.33,5.08)$.

The third model was fitted for employed mothers. As a result, employed mothers who had three and above children were 3.5 times more likely to breastfeed exclusively than those who had below three children (AOR 3.48, 95\% CI 1.79, 6.78), employed mothers who had good knowledge of exclusive breastfeeding were more likely exclusively breastfeed (AOR 0.30, 95\% CI 0.11, 0.80), and also mothers who had no social support were 3.5 times more likely to breastfeed exclusively than those who have social support (AOR 3.46, 95\% CI 1.78, 6.72) (Table 5).

Table 3 Independent predictors of exclusive breastfeeding for both employed and unemployed mothers (Full model) in Gondar town, northwest Ethiopia, October, 2015

\begin{tabular}{|c|c|c|c|c|c|}
\hline \multirow[t]{2}{*}{ Variables } & \multicolumn{2}{|c|}{ Exclusive breastfeeding } & \multirow[t]{2}{*}{$\operatorname{COR}(95 \% \mathrm{Cl})$} & \multirow[t]{2}{*}{ AOR $(95 \%$ C.I) } & \multirow[t]{2}{*}{$p$-value } \\
\hline & Yes & No & & & \\
\hline \multicolumn{6}{|l|}{ Birth Interval } \\
\hline $1-2$ years & 131 & 276 & $0.73(0.53,1.02)$ & $0.72(.50,1.05)$ & 0.085 \\
\hline 3 and above & 95 & 147 & 1 & 1 & \\
\hline \multicolumn{6}{|l|}{ Knowledge } \\
\hline Poor knowledge & 19 & 106 & $0.27(0.16,0.46)$ & $0.437(0.245,0.779)$ & 0.005 \\
\hline Good knowledge & 207 & 317 & 1 & 1 & \\
\hline \multicolumn{6}{|l|}{ Place of birth } \\
\hline Home & 12 & 55 & $0.38(0.20,0.72)$ & $0.53(0.26,1.09)$ & 0.084 \\
\hline Health center & 214 & 368 & 1 & 1 & \\
\hline \multicolumn{6}{|l|}{ Marital status } \\
\hline Married & 215 & 366 & $3.04(1.56,5.93)$ & $1.88(0.91,3.89$ & 0.087 \\
\hline Unmarried & 11 & 57 & 1 & 1 & \\
\hline \multicolumn{6}{|l|}{ Employment status } \\
\hline Unemployed & 160 & 173 & $3.50(2.48,4.95)$ & $3.43(2.38,4.95)$ & .0001 \\
\hline Employed & 66 & 250 & 1 & 1 & \\
\hline \multicolumn{6}{|l|}{ Attitude towards EBF } \\
\hline Poor Attitude & 6 & 103 & $0.84(0.04,0.20)$ & $0.13(0.05,0.31)$ & .0001 \\
\hline Good Attitude & 220 & 319 & 1 & 1 & \\
\hline
\end{tabular}


Table 4 Multivariate analysis of exclusive breastfeeding among unemployed mothers Gondar town, northwest, October, 2015

\begin{tabular}{|c|c|c|c|c|c|}
\hline \multirow[t]{2}{*}{ Variables } & \multicolumn{2}{|c|}{ Exclusive breastfeeding } & \multirow[t]{2}{*}{ COR $(95 \% \mathrm{Cl})$} & \multirow[t]{2}{*}{ AOR $(95 \% \mathrm{Cl})$} & \multirow[t]{2}{*}{$p$ - value } \\
\hline & Yes & No & & & \\
\hline \multicolumn{6}{|l|}{ Birth Interval } \\
\hline $1-2$ years & 92 & 120 & $0.60(0.38,0.94)$ & $0.63(0.38,1.03)$ & 0.085 \\
\hline 3 and above & 68 & 53 & 1 & 1 & \\
\hline \multicolumn{6}{|l|}{ Knowledge on EBF } \\
\hline Poor knowledge & 14 & 48 & $0.250(0.13,0.47)$ & $0.28(0.14,0.54)$ & 0.0001 \\
\hline Good knowledge & 146 & 125 & 1 & 1 & \\
\hline \multicolumn{6}{|l|}{ Social support } \\
\hline No & 11 & 33 & $0.31(0.15,0.64)$ & $0.33(0.16,0.71)$ & 0.004 \\
\hline Yes & 149 & 140 & 1 & 1 & \\
\hline \multicolumn{6}{|l|}{ Place of birth } \\
\hline Home & 9 & 24 & $0.37(0.17,0.82)$ & $0.47(0.20,1.10)$ & 0.082 \\
\hline Health center & 151 & 149 & 1 & 1 & \\
\hline \multicolumn{6}{|l|}{ Antenatal care } \\
\hline No & 29 & 56 & $0.46(0.28,0.77)$ & $0.56(0.32,0.98)$ & 0.042 \\
\hline Yes & 131 & 117 & 1 & 1 & \\
\hline \multicolumn{6}{|l|}{ Mode of delivery } \\
\hline Vaginal & 145 & 134 & $2.81(1.48,5.34)$ & $2.60(1.33,5.08)$ & 0.005 \\
\hline CS & 15 & 39 & 1 & 1 & \\
\hline
\end{tabular}

EBF exclusive breastfeeding, COR Crude odds ratio and $A O R$ adjusted odds ratio

Table 5 Multivariate analysis of exclusive breastfeeding among employed mothers in Gondar town, northwest Ethiopia, October, 2015

\begin{tabular}{|c|c|c|c|c|c|}
\hline \multirow[t]{2}{*}{ Variables } & \multicolumn{2}{|c|}{ Exclusive breastfeeding } & \multirow[t]{2}{*}{ COR $(95 \% \mathrm{Cl})$} & \multirow[t]{2}{*}{ AOR $(95 \% \mathrm{Cl})$} & \multirow{2}{*}{$\begin{array}{l}p- \\
\text { value }\end{array}$} \\
\hline & Yes & No & & & \\
\hline \multicolumn{6}{|l|}{ Parity } \\
\hline 1-2 children & 130 & 46 & 1 & 1 & 0.085 \\
\hline 3 and above & 120 & 20 & $2.12(1.19,3.79)$ & $3.48(1.79,6.78)$ & 0.0001 \\
\hline \multicolumn{6}{|l|}{ Knowledge on BF } \\
\hline Good knowledge & 61 & 192 & 1 & 1 & \\
\hline Poor knowledge & 5 & 58 & $0.27(0.10,0.71)$ & $0.30(0.11,0.80)$ & 0.016 \\
\hline \multicolumn{6}{|l|}{ Social support } \\
\hline Yes & 58 & 26 & 1 & 1 & \\
\hline No & 194 & 40 & $2.17(1.26,4.01)$ & $3.46(1.78,6.72)$ & 0.0001 \\
\hline \multicolumn{6}{|l|}{ Place of birth } \\
\hline Home & 31 & 3 & 1 & 1 & \\
\hline Health center & 219 & 63 & $0.34(0.10,1.14)$ & $0.36(0.10,1.28)$ & 0.115 \\
\hline \multicolumn{6}{|l|}{ Wealth } \\
\hline Lower & 13 & 71 & 1 & 1 & \\
\hline Medium & 24 & 85 & $0.593(0.288,1.223$ & $0.38(0.17,0.85)$ & $0.018^{*}$ \\
\hline Higher & 29 & 94 & $0.915(0.495,1.693)$ & $1.00(0.52,1.93)$ & 0.997 \\
\hline
\end{tabular}


Likewise, women in the wealth index ranking middle were $62 \%$ less likely to EBF than lower rank (AOR 0.38, 95\% CI 0.17, 0.85).

\section{Discussion}

As a global public health recommendation, infants should be fed breast milk only for the first six months, because breastmilk is hygienic compared with other fluids and contains all the nutrients and antibodies that are very important to prevent disease months [14]. However, employed mothers may return to work early after giving birth for various reasons. If not supported by their employers, they can be separated from their babies, have difficulty expressing and storing milk and thus not be able to maintain exclusive breastfeeding [10].

This study revealed that the prevalence of exclusive breastfeeding practice was $20.9 \%$ among employed mothers and $48.0 \%$ among unemployed mothers. This result was lower for both employed and unemployed mothers as compared to the study conducted in different parts of Ethiopia such as; a study conducted in Mecha found $44 \%$ of employed and $65 \%$ unemployed mothers practice [12], and another study found 33\% of employed and $73 \%$ of unemployed mothers breastfed their children for six months exclusively [7].

Employment status was significantly associated with exclusive breastfeeding practice which was supported in a study conducted in Goba, southern Ethiopia [7]. In this study, unemployed mothers were more likely to practice EBF than employed ones. This finding was consistent with studies done in Saudi Arabia [15], Canada [16] and Guatemala [17]. This might be due to the fact that unemployed mothers get a longer time to stay with their children [18]. Similar findings were found in many studies which confirmed that a mothers' work status has a negative association with exclusive breastfeeding practices. In addition to EBF, the working status of mothers also shorten the duration of breastfeeding $[19,20]$. A study in Guatemala city also confirmed that women who did not work outside the home were $32 \%$ times more likely to exclusively breastfeed as were women who worked outside the home [17].

The majority of employed mothers started breastfeeding their children with liquids and food supplementations earlier as compared to their unemployed counterparts and they frequently attribute early weaning to unsupportive work environments [21]. The possible reason might be employment rules and regulations, such as less maternity leave (three months in Ethiopian context), and employed mothers have less opportunity to stay at home, compromising exclusive breastfeeding and lack child care facilities close to the workplace [20].

In this study mothers who have three and above children were 3.5 times more likely to breastfeed exclusively than those who had one or two children. This could be because of the fact that multipara mothers might be more experienced and knowledgeable on the advantage of exclusive breastfeeding [22]. This finding is inconsistent with studies done in Saudi Arabia and Canada $[16,23]$. In contrast, a study done in Bahirdar, Ethiopia reported that mothers who were primipara were two times more likely to exclusively breastfeed than multipara mothers [8].

According to our study, mothers who had poor knowledge about the recommended duration of EBF were $70.4 \%$ less likely to breastfeed exclusively than those who had good knowledge, which is similar to results found in Southern Ethiopia [24].

Employed mothers ranking a middle wealth index scores were associated with shorter duration of exclusive breastfeeding than the lower ranking. The plausible reason might be that middle wealthy mothers were in good economic conditions, had less stress conditions and could use other breastmilk substitutes [18]. But this finding contradicts with results found in a study conducted in Ethiopia in that being middle/ richer/richest wealth index was retained as positive predictors of EBF [5] and also a study was done in Sudan [25].

Regarding the associated factors of exclusive breastfeeding among unemployed mothers, those who had poor knowledge on exclusive breastfeeding were less likely to breastfeed exclusively than those who had good knowledge. This result is supported by Mecha and southern Ethiopia findings. This might be due to unemployed mothers having poor knowledge did not understand the disadvantages of EBF [22].

Social support is another factor important for breastfeeding [20]. However, in this study employed mothers who were not socially supported were more likely to breastfeed exclusively than those who have social support. The possible explanation for this might be these mothers were obliged to leave their children with somebody else who care for their children at home. That means mothers who want to leave their children for work may search and find someone to take care of their children. Thus, these mothers present with higher social support during the survey.

Unlike their employed counterparts, in this study, unemployed mothers who had no social support were less likely to breastfeed exclusively than those who were supported. A similar finding in Goba showed support from spouse favors mothers to exercise exclusive breastfeeding [7]. In the same way results in the USA showed that a positive influence of support for breastfeeding initiation and duration in that $57 \%$ of mothers considered their support group to be lightly or moderately important in influencing their decision to breastfeed beyond a year [26]. The possible explanation could be mothers 
who had a social support have the benefit of improving satisfaction with the infant feeding experience with people around them [27].

Unemployed mothers who had no ANC follow up as per the recommended frequency were $43.7 \%$ less likely to breastfeed exclusively than those who had ANC follow up. This was supported by findings in America where black mothers who had an antenatal care breastfed their infants for longer durations [28]. The possible reason might be antenatal care based educational programs had the greatest effect of any single intervention on both initiation and duration of EBF [29].

Those unemployed mothers who delivered vaginally were more likely to breastfeed exclusively than those who were delivered by caesarean section. This finding was consistent with a study from Canada [16]. The rationale behind might be due to the fact that mothers who delivered by caesarean section often find it difficult to achieve a comfortable position for breastfeeding.

\section{Limitations of the study}

This study was not supplemented with a qualitative study. We didn't study the employment characteristics, such as time and sector. There might be misclassification of mothers on their attitude status due to the fewer number of questions. There might be recall bias since mothers were interviewed to recall their experience. Our data collection tool was not validated this might limit the findings generalizability.

\section{Conclusion}

A large proportion of infants were not exclusively breastfed by both employed and unemployed mothers. The duration of EBF was below the WHO recommendation and the target of the Ethiopian health sector development plan. This study has indicated employed mothers are less likely to practice exclusive breastfeeding than unemployed mothers. The exclusive breastfeeding status of unemployed mothers was significantly better than that of employed mothers. Parity, knowledge about exclusive breastfeeding, social support, and maternal wealth index were independent predictors of exclusive breastfeeding among employed mothers. While the knowledge on exclusive breastfeeding, social support, antenatal care and mode of delivery were independent predictors of exclusive breastfeeding of unemployed mothers. A different approach of intervention should be implemented to employed and unemployed mothers to promote exclusive breastfeeding.

\section{Additional file}

Additional file 1: Table S1. Descriptive statistics on demographic, knowledge and attitude characteristics of mothers having children of age 7-12 months in Gondar town, October 2015. (DOCX 14 kb)

\section{Abbreviations}

ANC: antenatal care; BF: breastfeeding; CSA: Central statistical agency; EBF: exclusive breastfeeding; EBFP: exclusive breastfeeding practice; EDHS: Ethiopian demographic and health survey; FMOH: Federal ministry of health; HIV: Human immunodeficiency virus; HSDP: Health sector development program; IYCF: Infant and young child feeding; NGO: Non Governmental organization; MDG: Millennium development goal; ORS: Oral rehydration salt; SDG: Sustainable development goals; SSSF: Solid Semi-Solid and soft food; ANRS: Amhara national regional state; UNICEF: United nations children's fund; USAID: United State agency for international development; WHO: World health organization

\section{Acknowledgements}

We would like to thank University of Gondar, Amhara Regional Health Bureau, and Gondar town administration. We are also glad for mothers who participated in this study.

\section{Funding}

Not applicable

\section{Availability of data and materials}

The datasets used and/or analysed during the current study are available from the corresponding author on reasonable request.

\section{Authors' contributions}

DAC wrote the proposal, participated in data collection, analyzed the data and drafted of the paper. GAB and YAG approved the proposal with some revisions, participated in data analysis and revised subsequent drafts of the paper. YAM drafted the manuscript and participated in a subsequent revision. All authors read and approved the final manuscript.

\section{Authors' information \\ DAC- MSC in applied human nutrition, capacity building forecasting officer in pharmaceuticals fund and supply agency, Gondar, Ethiopia. \\ GAB- PhD in Public Health and Associate Professor in the Institute of Public Health, University of Gondar, Ethiopia \\ YAG-MPH in Epidemiology and Biostatistics, Lecturer in the Institute of Public Health, University of Gondar, Ethiopia \\ YAM- MPH in Epidemiology and Biostatistics, Lecturer in the Institute of Public Health, University of Gondar, Ethiopia}

\section{Competing interests}

The authors declare that they have no any competing interests.

\section{Consent for publication}

Not applicable

\section{Ethics approval and consent to participate}

Ethical clearance was obtained from the ethical review committee of the Institute of Public Health, College of Medicine and Health Sciences University of Gondar. After obtaining ethical approval, written permission was obtained from Gondar town administration health department and verbal informed consent was obtained from each study participant.

All study participants were informed that participation in this research project has no incentives or direct benefit. Participant's involvement in the study was on a voluntary basis; participants who are unwilling to participate in the study and those who wish to quit their participation at any stage were informed to do so without any restriction.

\section{Author details}

${ }^{1}$ Ethiopian Public Health Institute, Addis Ababa, Ethiopia. ${ }^{2}$ Department of Health Service management and Health Economics, Institute of Public Health, College of Medicine and Health Science, University of Gondar, Gondar, Ethiopia. ${ }^{3}$ Department of Epidemiology and Biostatistics, Institute of Public Health, College of Medicine and Health Science, University of Gondar, Gondar, Ethiopia. 
Received: 27 July 2016 Accepted: 11 June 2017

Published online: 17 June 2017

\section{References}

1. WHO. Exclusive breastfeeding: WHO; 2015 [Available from: http://www.who. int/nutrition/topics/exclusive_breastfeeding/en/.

2. Ssenyonga R, Muwonge R, Nankya I. Towards a better understanding of exclusive breastfeeding in the era of HIV/AIDS: a study of prevalence and factors associated with exclusive breastfeeding from birth, in Rakai, Uganda. J Trop Pediatr. 2004;50(6):348-53.

3. WHO. Infant and young child feeding: WHO; 2015 [updated September 2016 Available from: http://www.who.int/mediacentre/factsheets/fs342/en/.

4. Jennings J, Hirbaye M. Review of incorporation of essential nutrition actions into public health programs in Ethiopia. Washington DC: The Food and Nutrition Technical Assistance Project (FANTA) Equinet Newsletter. 2008:1-25.

5. Alemayehu T, Haidar J, Habte D. Determinants of exclusive breastfeeding practices in Ethiopia. Ethiop J Health Dev. 2009;23(1):12-18.

6. Rutstein SO. The DHS Wealth Index: Approaches for rural and urban areas. 2008

7. Setegn T, Belachew T, Gerbaba M, Deribe K, Deribew A, Biadgilign S Factors associated with exclusive breastfeeding practices among mothers in Goba district, south east Ethiopia: a cross-sectional study. Int Breastfeed J. 2012;7:1-8.

8. Seid AM, Yesuf ME, Koye DN. Prevalence of exclusive breastfeeding practices and associated factors among mothers in Bahir Dar city, Northwest Ethiopia: a community-based cross-sectional study. Int Breastfeed J. 2013;8:1-8.

9. Fein SB, Roe B. The effect of work status on initiation and duration of breastfeeding. Am J Public Health. 1998;88(7):1042-6.

10. Abdulwadud OA, Snow ME. Interventions in the workplace to support breastfeeding for women in employment. The Cochrane Library. 2007.

11. Demographic E. Health Survey 2011 Central Statistical Agency Addis Ababa. Ethiopia ICF International Calverton, Maryland, USA March. 2012.

12. Mekuanint Taddele LA. Netsanet Fentahun. Exclusive breastfeeding and maternal employment in Ethiopia: A comparative cross- sectional Study. International Journal of Nutrition and Food Sciences. 2014;3(6):497-503.

13. Krapp KM, Wilson J. The Gale Encyclopedia of Children's Health: DK: Gale Cengage; 2005.

14. WHO, UNICEF. Global strategy for infant and young child feeding. Geneva: World Health Organization; 2003.

15. El-Gilany A-H, Shady E, Helal R. Exclusive breastfeeding in Al-Hassa, Saudi Arabia. Breastfeed Med. 2011;6(4):209-13.

16. Al-Sahab B, Lanes A, Feldman M, Tamim H. Prevalence and predictors of 6month exclusive breastfeeding among Canadian women: a national survey. BMC Pediatr. 2010;10(1):20.

17. Dearden K, Altaye M. Maza Id, Oliva Md, Stone-Jimenez M, Morrow AL, et al. Determinants of optimal breast-feeding in peri-urban Guatemala City, Guatemala. Rev Panam Salud Publica. 2002;12(3):185-92.

18. Sjölin S, Hofvander Y, Hillervik C. Factors related to early termination of breastfeeding a retrospective study in Sweden. Acta Paediatr. 1977; 66(4):505-11.

19. Tan KL. Factors associated with exclusive breastfeeding among infants under six months of age in peninsular Malaysia. Int Breastfeed J. 2011;6:1-7.

20. Thulier D, Mercer J. Variables associated with breastfeeding duration. J Obstet Gynecol Neonatal Nurs. 2009;38(3):259-68.

21. Ortiz J, McGilligan K, Kelly P. Duration of breast milk expression among working mothers enrolled in an employer-sponsored lactation program. Pediatr Nurs. 2004;30(2):111-9.

22. Kronborg $\mathrm{H}$, Vaeth $\mathrm{M}$. The influence of psychosocial factors on the duration of breastfeeding. Scand J Public Health. 2004;32(3):210-6.

23. Amin T, Hablas $H, A l$ Qader AA. Determinants of initiation and exclusivity of breastfeeding in Al Hassa, Saudi Arabia. Breastfeed Med. 2011;6(2):59-68.

24. Kassa Eshetu Modjo1 NWA. Attitude and Practice Towards Exclusive Breast Feeding and Its Associated Factors Among HIV Positive Mothers in Southern Ethiopia. American Journal of Health Research. 2015;3(2):105-15.

25. Mohammed SGS. Infants feeding and weaning practices among mothers in northern kordofan state, Sudan. European Scientific Journal. 2014;10(24): $165-81$

26. Hills-Bonczyk SC, Tromiczak KR, Avery MD, Potter S, Savik K, Duckett LJ. Women's experiences with breastfeeding longer than 12 months. Birth. 1994;21(4):206-12.
27. Dennis C-L, Hodnett E, Gallop R, Chalmers B. The effect of peer support on breast-feeding duration among primiparous women: a randomized controlled trial. Can Med Assoc J. 2002;166(1):21-8.

28. Kistin N, Benton D, Rao S, Sullivan M. Breastfeeding rates among black urban low-income women: effect of prenatal education. Pediatrics. 1990;86(5):741-6.

29. Guise J-M, Palda V, Westhoff C, Chan BK, Helfand M, Lieu TA. The effectiveness of primary care-based interventions to promote breastfeeding: systematic evidence review and meta-analysis for the US Preventive Services Task Force. The Annals of Family Medicine. 2003;1(2):70-8.

\section{Submit your next manuscript to BioMed Central and we will help you at every step:}

- We accept pre-submission inquiries

- Our selector tool helps you to find the most relevant journal

- We provide round the clock customer support

- Convenient online submission

- Thorough peer review

- Inclusion in PubMed and all major indexing services

- Maximum visibility for your research

Submit your manuscript at www.biomedcentral.com/submit
) Biomed Central 